\title{
BMJ Open Group-based intervention to improve developmental status among children age 6-18 months in rural Shanxi province, China: a study protocol for a cluster randomised controlled trial
}

To cite: Xu M, Liu A, Zhao C, et al. Group-based intervention to improve developmental status among children age 6-18 months in rural Shanxi province, China: a study protocol for a cluster randomised controlled trial. BMJ Open 2020;10:e037156. doi:10.1136/ bmjopen-2020-037156

- Prepublication history and additional material for this paper are available online. To view these files, please visit the journal online (http://dx.doi org/10.1136/bmjopen-2020037156).

Received 04 February 2020 Revised 20 August 2020 Accepted 17 September 2020

Check for updates

(C) Author(s) (or their employer(s)) 2020. Re-use permitted under CC BY-NC. No commercial re-use. See rights and permissions. Published by BMJ.

For numbered affiliations see end of article.

Correspondence to

Dr Hongyan Guan;

cip_ghy@yeah.net

\section{ABSTRACT}

Introduction Early childhood development (ECD) is a critical component for building the foundation of future physical and emotional health and subsequent academic success. The quality of the home environment to promote development is an important factor in ECD. Since large rural-urban disparities in the home environment exist in China, there is a critical need to develop and evaluate interventions to promote ECD in rural areas. Individual center-based or home-based interventions dominate the current ECD programmes in rural China. However, group-based interventions offer potential advantages in terms of both effectiveness and cost. Thus, we aim to: (1) evaluate the effectiveness of an integrated group-based intervention, the Care Group Intervention, in enhancing ECD among children age 6-18 months and (2) conduct a cost-effectiveness analysis.

Methods and analysis The Care Group Intervention uses a cluster (by township) randomised controlled trial conducted in Fenxi county, Shanxi province, China, from July 2019, for 1 year. The intervention focuses on five key components of nurturing care including good health, adequate nutrition, responsive caregiving, security and safety, and opportunities for early learning. The intervention comprises small groups of 3-10 children within a certain age range and their primary caregivers that are led by well-trained local facilitators. Outcomes includes infants' developmental quotient (Bayley Scales of Infant Development III, Ages \& Stages Questionnaire: Social-Emotional, second edition); anaemia (HemoCue $\mathrm{Hb} 301+$ ); nurturing environment (Infant/Toddler Home Observation for Measurement of the Environment), parentchild interaction (Teaching Scale) and caregiver depression (Center for Epidemiological Studies Depression). Cost data are collected throughout the entire study to carry out a cost-effectiveness analysis.

Ethics and dissemination This study was approved by the Ethical Committee of Capital Institute of Pediatrics, Beijing, China on 10 July 2018 (SHERLL2018014). Findings and results from this project will be disseminated via publications and presentations.

Trial registration number Chinese Clinical Trials Registry: ChiCTR1900022894. Registered on 30 April 2019.
Strengths and limitations of this study

- This study fills a gap in the evidence regarding small group-based early childhood development (ECD) interventions for at risk rural Chinese children aged 6-18 months.

- Documenting cost-effectiveness will provide a solid evidence-based foundation for the implementation of future national official recommendations and policies for ECD in rural China.

- This study will explore the feasibility of extending current essential child healthcare service within the rural public health system.

- The limitations of this project are the possible loss to follow-up and limited operational capacity of facilitators.

\section{INTRODUCTION}

There are 250 million children ( $43 \%$ of whom are under aged 5 years) in low-income and middle-income counties who are at risk of having a compromised development trajectory. Inadequate home stimulation as well as other health and environmental factors may lead to developmental delay. It is estimated that as many as 15 million children under age 5 years in China are unable to fully realise their developmental potential. China ranks as having the third highest number of children with poor development in the world. ${ }^{1}$ In rural areas, only $57.4 \%$ of children have two or more toys and only $21.5 \%$ have three or more books. ${ }^{2}$ Children with a persistent developmental delay in early life will limit their developmental trajectory leading to a decline in health status, work income and life satisfaction in adulthood. ${ }^{3-5}$ High-quality early childhood development (ECD) projects can return as much as US\$6-17 for every US $\$ 1$ invested. ${ }^{6}$ Therefore, interventions to 
support and improve ECD are positioned as fundamental approaches to break intergenerational poverty; one of the major sustainable development goals.

Unequal resource allocation negatively contributes to the observed rural-urban disparity in ECD in China. ${ }^{8}$ Cognitive scores among infants in rural areas of Shaanxi province has been demonstrated to be significantly lower than those of infants in urban areas. ${ }^{9}$ As many as $13.4 \%$ of infants in rural Shaanxi have a severe risk of cognitive delay based on the Bayley Scales of Infant Development III (BSID-III) ${ }^{10}$ According to a survey conducted in six poverty-stricken counties of Guizhou and Shanxi provinces during $2013,37 \%$ of children aged $0-3$ years had suspected developmental delay based on Ages \& Stages Questionnaires (ASQs, third edition) and 59.8\% had at least one problem of nutrition, disease or physical development. ${ }^{2}$ As a predictive factor of cognitive development, anaemia is another prevalent concern for rural children. One study reported that $54.3 \%$ of infants in poor rural China were anaemic, while $24.3 \%$ of whom had moderate/severe anaemia. ${ }^{11}$

Considering the large numbers of children with poor development in China, the Chinese government has made a series of efforts aimed at promoting ECD. The Outline of the Program for Chinese Children's Development (2011-2020) explicitly sets out main goals and coping strategies for promoting child development through four aspects, namely health, education, legal protection and environment, covering both urban and rural children. ${ }^{12}$ The Plan for the Development of Children in Poor Areas (2014-2020) concentrates on improving nutrition, disease prevention, protection and education for young rural children in all of the 680 national-level povertystricken counties. ${ }^{13}$ Recently, the Guidelines of the State Council on Promoting the Development of Nurturing Care Services for Children Under 3 clearly states that the responsibility of nurturing for children aged 0-3 years should be family oriented, and the development of service should emphasise providing professional guidance for families. ${ }^{14}$

To our knowledge, previous ECD interventions in China have involved both individual intervention and group intervention. The Care for Child Development intervention targets developmental progress through responsive caregiving, nutrition and nurturing care without any games or activities. ${ }^{15}$ Reach Up focuses on development of specific child abilities (cognition, language, motor and socioemotion) with developmentally appropriate games and instructions but does not include any component of nutritional or child health support. ${ }^{16}$ Integrated ECD carries out nurturing care intervention conducted by group games, dialogic reading activities and counselling during basic physical examination, may prevent developmental delay in some children. ${ }^{17}$ Luo et al found that home visits that included health promotion and psychosocial stimulation conducted by community health workers is a practical approach to promote development for children aged 6-18 months. ${ }^{18}$ A study on nutrition intervention towards child development conducted by the same research team found that the micronutrient powder improved haemoglobin levels for children aged 6-11 months. ${ }^{19}$

Evidences have showed that group-based intervention has the advantage of being less costly. ${ }^{2021}$ However, current group-based interventions whose participants are usually unfixed and of large age interval, which may weaken the effectiveness. Small group-based intervention with fixed population might solve this concern. A fixed group can foster a stronger sense of community and help caregivers to reduce feeling of isolation and depression. In addition, it is conducive to modelling a positive parenting environment through promoting mutual learning and peer support among caregivers, while giving caregivers tools and skills of nurturing care. Experiences in Pakistan and Bangladesh have shown that small group-based interventions on nurturing care and child development contribute to children's language, cognitive, motor and social development, as well as improved caregivers' nurturing knowledge and maternal depression. ${ }^{22}{ }^{23}$ However, there is no evidence regarding small group-based ECD interventions for at risk rural young children in China yet.

In this project, we will apply a small group-based intervention, the Care Group Intervention, in Fenxi county, Shanxi province for 1 year, to explore its effect on the outcome of child development and nurturing care ability and depression among primary caregivers. Meanwhile, we will conduct a cost-effectiveness analysis to examine both the costs and outcomes of the intervention. This project will fill the gap of lacking evidence of small group-based intervention on ECD for rural Chinese children aged 6-18 months. In addition, documenting cost-effectiveness will provide a solid evidence-based foundation for implementation of future official recommendations and policies for ECD in rural China.

\section{STUDY HYPOTHESIS}

Children's ECD as measured by BSID-III Score (language, cognition and motors skill) will be significantly improved by the Care Group Intervention with those in the intervention group improving by 0.24 standard deviation (3.6 point) than those who in control group.

\section{METHODS}

\section{Trial design}

The Care Group Intervention uses a cluster (by township) randomised controlled trial conducted in Fenxi county, Linfen city, Shanxi province, China from July 2019, for 1 year. Clusters were created at the level of town rather than villages as there were not enough participants at village level to create groups. In addition, separating the groups by town enabled us to prevent contamination across clusters where knowledge from the intervention might be shared among caregivers. The intervention focuses on five key components, which included good 
health, adequate nutrition, responsive caregiving, security and safety, and opportunities for early learning under the framework of nurturing care promoted by WHO and UNICEF. The intervention comprises small groups of 3-10 children within a certain age range and their primary caregivers that are led by well-trained facilitators in the same town. Frequencies are two times per month for children aged 6-23 months and once a month for children aged 24-30 months. Intervention materials were designed by researchers, including the Care Group Manual, Toolkit and Flipcharts. Programme evaluation conducted at baseline, mid-term and endline includes infants' developmental quotient; anaemia; nurturing environment, caregiver depression and parent-child interaction (PCI). Cost data are collected throughout the entire study to carry out a cost-effectiveness analysis.

\section{Implementation site}

This trial is being conducted in Fenxi county, Linfen city, Shanxi province, China. Shanxi province is located in central China, with an area of $156700 \mathrm{~km}^{2}$, and around $80 \%$ of the land area is mountainous. The total population is 36.64 million by the year of 2015 , and rural population occupied $44.97 \% .{ }^{24}$ By the year of 2017 , per capita disposable income in rural and urban Shanxi were 29131 RMB (US\$4094) and 10781 RMB (US\$1515), respectively. ${ }^{25}$

Fenxi county is a national-level poverty-stricken (The national-level poverty-stricken county is a standard set by the Chinese government for helping poverty-stricken areas. Per capita net income is the criteria to evaluate whether a county meets the standard. By May 2019, there were 485 poverty-stricken counties distributed in 22 provinces in China.) county located in southern Shanxi province, at the northern end of Linfen city, with a total area of $880 \mathrm{~km}^{2}$. By the year of 2018, permanent resident population was 150398 , and rural population occupied $53.32 \%$. In 2018, the annual per capita disposable income in rural and urban Fenxi county were 27125 RMB (US\$3812) and 4267 RMB (US\$600), respectively. ${ }^{26}$ According to the Fenxi Annual Report on Maternal and Child Health (unpublished data), there were 925 live births in 2018. Fenxi has jurisdiction over 8 townships and 1 community that includes 120 administrative villages and 6 neighbourhood committees. Care Group Intervention were conducted in these 120 administrative villages.

\section{Intervention and control Intervention}

The intervention emphasises early learning, responsive caring, security and safety, healthcare, feeding and nutrition, and child protection. The small group session lasting about $45 \mathrm{~min}$ has the following standard structure:

1. Welcome and check-in (5 min).

2. Health class $(5-10 \mathrm{~min})$.

3. Nurturing class (5-10 min).

4. Activity ( $20 \mathrm{~min})$.

5. Language power ( $5 \mathrm{~min})$.

6. Closing (2 $\mathrm{min})$.
Each session starts with a welcome song, review of key messages and a question and answer session. In each session, both the health and the nurturing care sessions cover one topic each. In the health session, half of the class is to address feeding and nutrition; the other half covers disease prevention, healthcare, injury prevention and mental healthcare. In the nurturing care session, topics include child developmental milestones, early learning, responsive caring, and security and safety. Activity is introduced to assist primary caregivers in practicing what they learnt in nurturing classes and to encourage children to enjoy and learn in a positive environment full of warmth and love. Owing to children's limited attention span and individual interests, activities should be interesting and attractive. Additional optional activities are provided. A specific focus on language has been provided through using a small stuffed finger puppet to provide activities. This has been shown by an author (SB) to increase parent talking and interactions in both Guatemala and Colorado. ${ }^{27}$ For younger children whose receptive language is much developed than expressive language, finger puppet can promote language use. For older children who are able to talk better, they can choose either finger puppet games or a song in this session. The closing portion that ends each session includes suggestions that caregivers can practice at home and planning for the next session (date, time and content). Children and primary caregivers are encouraged to stay at the centres after each session to practice what they have learnt, give their personal opinions and reflections and to promote children interacting with their peers.

Facilitators are required to register the following information before each session starts: date, session name, relationship of the caregiver with the child. To encourage participation, facilitators are required to communicate with participants 1 day before each session by WeChat, a very popular social networking mobile software.

The intervention is delivered fortnightly by well-trained facilitators to groups of 3-10 caregiver-child dyads. Age difference in each group should be within 3 months. Ideally, children can participate in the Care Group Intervention from 2 months of age. However, local infants are typically kept indoors for the first 100 days of life because adults feel that newborns are too vulnerable to be able to withstand the outdoor environment. In addition, the BSID-III can only be used for developmental assessment from age 4 months.

Existing local child activity centres funded by UNICEF are the preferred intervention site. However, if the centre is too far from the infant's home, accessible service point/facilitators' or participants' homes is also suggested when meeting the following requirements: (1) larger than $20 \mathrm{~m}^{2}$ and (2) not far than $5 \mathrm{~km}$ from all the infants' home; (3) quiet and clean enough to conduct all activities. All toys and hands on materials are provided by the research programme and must be cleaned appropriately in the morning on the day of the intervention. 
Table 1 Summary of topics in the Care Group Manual

\begin{tabular}{|c|c|c|c|c|c|}
\hline Health Class & 56 & Nurturing class & 56 & Activities for child development & 84 \\
\hline Feeding and nutrition & 28 & Early learning & 23 & Social-emotional development & 20 \\
\hline Disease prevention & 10 & Responsive caring & 17 & Language development & 15 \\
\hline Injury prevention & 4 & Security and safety & 10 & Cognitive development & 19 \\
\hline $\begin{array}{l}\text { Mothers' mental } \\
\text { healthcare }\end{array}$ & 4 & $\begin{array}{l}\text { Others (kindergarten preparation, } \\
\text { etc) }\end{array}$ & 2 & $\begin{array}{l}\text { Feeding and complementary food } \\
\text { preparation }\end{array}$ & 4 \\
\hline
\end{tabular}

\section{Control}

Participants in both the intervention and control groups receive free vaccination and health management services for children aged 0-6 years. Both services are part of the National Public Health Service (NPHS), according to the National Standards for Basic Public Health Service issued by the National Health Commission of the People's Republic of China in 2009, and implemented nationwide. $^{28}$ The vaccination service includes vaccination management, implementation and handling of adverse events following immunisation. The health management service includes 13 interviews (less than 7 days after delivery, at 30 days and at age 3, 6, 8, 12, 18, 24, 30, 36, 48, 60 and 72 months) including basic physical examination and developmental assessment, and health guidance according to the children's age.

\section{Intervention tools}

Care Group Intervention tools include the Care Group Manual, Care Group Toolkit and Care Group Flipcharts. The Care Group Manual guides facilitators in leading each activity. The Care Group Toolkit is a $40 \times 50 \times 60 \mathrm{~cm}$ plastic box including toys, learning tools, books and children's tableware. There are 36 pieces of material in total. Each centre has an MP3 player. All toys should be safe, clean, reusable and inexpensive. The Care Group
Flipcharts function as helpful reminders for facilitators to deliver key messages of health classes. For each health topic, research members summarised a core message with rhyme to help caregivers to remember. See online supplemental file, Development of Care Group Manual, to know the specific developmental process of manual.

A summary of the topics in the Care Group Manual and examples of sessions $6-8$ and are listed in tables 1 and 2 .

\section{Facilitator}

From the previous qualitative interviews, it was clear that personal ability and work experience are the key elements needed for those who will become facilitators for our programme. Therefore, no particular vocational restriction was set during recruitment, except village doctors who were excluded owing to their current heavy workload and older age. Local people including health and family planning personnel, experienced volunteers, female caregivers, and kindergarten teachers were recruited, and nine facilitators were enrolled after interview. To prevent disengagement with the programme, it was imperative that facilitators lived in the same townships making them more likely to be more familiar with local caregivers. A progressive increase in salary is designed to encourage facilitators' engagement. They will get 900, 1200, 1500

Table 2 Examples of sessions for children aged 6 to 8 months

\begin{tabular}{|c|c|c|c|}
\hline Session & Health class & Nurturing class & Activities for child development \\
\hline $6-1$ & Food allergy & Positive feeding & Feeding our babies \\
\hline $6-2$ & $\begin{array}{l}\text { Prevention of vitamin D } \\
\text { deficiency rickets }\end{array}$ & - Instruction of solid food & Making yolk paste \\
\hline $7-1$ & $\begin{array}{l}\text { Timely addition of animal } \\
\text { foods }\end{array}$ & $\begin{array}{l}\text { Baby's social-emotional } \\
\text { development }\end{array}$ & $\begin{array}{l}\text { \#1 Express our feelings } \\
\text { \#2 Rhythm game }\end{array}$ \\
\hline $7-2$ & Fever care tips & $\begin{array}{l}\text { The importance of mother's } \\
\text { company }\end{array}$ & $\begin{array}{l}\text { How to brew Yingyangbao (Yingyangbao is a package } \\
\text { based on food matrix and contains high density of } \\
\text { multiple vitamins and minerals. The National Standards } \\
\text { Committee and the Ministry of Health issued the } \\
\text { standards of Yingyangbao in December } 2008 \text { (GB/ } \\
\text { t22570-2008) and it was implemented on } 1 \text { March } 2009 . \\
\text { It was freely distributed in lots of national-level poverty- } \\
\text { stricken counties to improve rural children's health and } \\
\text { development) }\end{array}$ \\
\hline
\end{tabular}


and $1800 \mathrm{RMB}$, respectively, in each season, equals to 450 RMB each month.

\section{Training}

Eight experts from national research institutes or children's hospitals, as well as research members, comprised the trainers. The nine facilitators were trained for 2 weeks in Fenxi county, Shanxi province 1 month before intervention started. Knowledge and activities, as well as skills to promote positive relationships and a warm environment, were specifically explained and demonstrated during the first week of training. Health topics were reinforced during the entire process because none of the facilitators had a previous professional medical background. During the second week, troubleshooting, practice and examination were the main targets. Retraining is provided regularly by three to four trainers, to address frequently asked questions and reinforce key messages.

\section{Supervision}

A three-level 'national-county-village' supervision mechanism was established to carry out project supervision. The frequencies at each level were set as quarterly, quarterly and monthly, respectively. The staff comprised nationallevel trainers, staff of the Fenxi government and Women and Child Health Care Station, and Maternal and Child Commissioner, respectively. Supervisory responsibilities at all levels are as follows. National-level supervisors are responsible for providing quarterly retraining and supervision; county-level supervisors are in charge of monthly data collection, judging whether a child with a problem requires a referral, and providing related assistance as well as monthly supervision; county-level supervisors are in charge of organising monthly class preparation and timely reporting of possible referrals.

\section{Sample size and power calculation}

With the mean of BSID-III Score is $100 \pm 15.0$, the Care Group Intervention is designed to increase children's BSID-III Score (motor, language and cognition) by 0.24 SDs. ${ }^{23}{ }^{29}$ With a $95 \% \mathrm{CI}$ and power of 0.80 , the minimum sample size was calculated as 216 per group by the software G*Power V.3.1. The valid data rate and follow-up rate were estimated as $80 \%$ and $80 \%$, respectively. Thus, 338 participants were required in each group, with a total 676 participants $(338 \times 2)$.

\section{Recruitment and randomisation}

The project intervention targets are all children aged 6-18 months in 120 administrative villages of Fenxi county. Recruitment was conducted 2 months before intervention was commenced by village doctors, who were required to clearly explain the content of the informed consent form to the children's legal guardians, emphasising programme advantages and voluntary participation according to personal circumstances. Each child's parent or legal guardian is required to sign the informed consent form after confirming their full understanding of the form.

\section{Inclusion and exclusion criteria}

The inclusion criteria are as follows: age 4-16 months at the time of recruitment; each child has at least one stable primary caregiver; and children and their primary caregivers have no plans to migrate within the next 1 year. The exclusion criterion was refusal to participate in the study.

Randomisation was performed after recruitment and the baseline survey. Eight townships were paired according to socioeconomic level. When more than two towns could be paired, we used the numbers of target population (children aged 6-18) to decide which two townships could be better paired. Each township was marked as A1, A2, B1, B2, C1, C2, D1 and D2 after four pairs were decided. We used IBM SPSS V.23.0 (IBM Corp) to randomly choose one number in each pair as intervention township. In turn, the other one in each pair was allocated as control township. All the children live in intervention/control townships were assigned as intervention/control group. Sengnian, Qingxiang, Dianping and Duizhu were allocated as intervention townships. Yongan, Heping, Xingjiayao and Tuanbai were allocated as control townships.

\section{Outcome measurement}

The primary outcome was set as children's developmental quotients, including language, motor, cognition and social-emotional (SE) Score. The BSID-III is used to asses children's language, motor, and cognition and the ASQ: SE, second edition (SE-2) is used to assess children's social emotional skills. Both BSID-III and ASQ:SE-2 have been examined as valid tools for Chinese children aged 0-3 years old. ${ }^{30-32}$

Secondary outcomes were set as haemoglobin level, family nurturing environment, PCI quality and caregiver depression. Two local medical personnel assess haemoglobin levels on site using a HemoCue $\mathrm{Hb} 301$ +haemoglobin detector with accuracy $0.1 \mathrm{~g} / \mathrm{L}$ (HemoCue, Angelholm, Sweden). We adopted indicators proposed by the WHO and UNICEF as the criteria for anaemia. ${ }^{33}$ Home stimulation is assessed by Infant/Toddler Home Observation for Measurement of the Environment (IT-HOME). The Chinese version has an acceptable reliability with the inter-rater consistency of 0.94 , and a good external validity. ${ }^{34} \mathrm{PCI}$ quality is assessed by Parent Child Teaching Scale (PCI Teaching Scales) developed by experts in University of Washington and Nursing Care Assessment Project team. ${ }^{35}$ Our research team has introduced PCI Scales into China by official approval. We found that the internal coefficient was 0.85 among 273 Chinese children under 3 years old (unpublished). The Center for Epidemiological Studies Depression (CES-D) Scale is designed to examine primary caregiver's depression.

Control variables were setas demographic characteristics including social economic status, the relationship of caregiver and child, child gender and age, order and number of birth, marital status, parents' and/or caregivers' education. We will also try to explore other possible mediators including frequent transfer of caregiver, utilisation rate 
of the NPHS, attendance, caregiver's satisfaction towards intervention. The Maternal and Child Health Handbook is used to record the utilisation rate of the NPHS. Attendance is recorded using a sign-in sheet at each session. A self-designed questionnaire (most items are derived from the Multiple Indicator Cluster Surveys developed by UNICEF) to survey household information. ${ }^{36}$

Project evaluation includes surveys at baseline, midterm and at the end of the intervention. The baseline survey was conducted in May 2019. Mid-term and endline surveys will be conducted at 6-7 and 12-13 months after the intervention begins. Satisfaction surveys are not conducted at baseline. The BSID-III will not be used at the mid-term survey. Besides peripheral blood sample collection that was conducted by two local medical personnel, all the evaluation will be conducted by qualified graduate students majored in Education or Psychology in Shanxi Normal University.

As for masking, only haemoglobin level were told to all caregivers on site.

\section{Cost-effectiveness analysis}

A cost-effectiveness analysis will be conducted to examine both the costs and outcomes of the Care Group Intervention. A societal perspective will be adopted. All costs related to the intervention will be included, that is, personnel, materials and transportation, using microcost methods. Both primary and secondary measures of effectiveness will be analysed. The primary effectiveness measures include child developmental indicators: BSID-III (language, motor, cognition) and ASQ:SE-2 (social emotion) Scores. Secondary effectiveness measures include haemoglobin level, IT-HOME (nurturing environment), PCI Teaching Scale (PCI quality) and CES-D (caregiver depression). The incremental cost-effectiveness ratio will be calculated to compare both costs and effectiveness of the intervention and control groups. Sensitivity analyses will be conducted, that is, personnel, materials and transportation using microcost measures, and the robustness of this economic analysis will be assessed. In the future, we will also compare our findings with other ECD interventions, at home (once they are available) and abroad.

\section{Quality control}

For quality control, interviewers were trained two times to use BSID-III, ASQ:SE-2, HOME and GoodData software and a 2 day practice was conducted before baseline started. First training was to systematically introduce questionnaires and software. The second training was conducted after 2 week practice to check reliability. Minimum of $85 \%$ consistency (intraclass correlation coefficient, ICC) was required for both BSID-III and ASQ:SE-2. Clips of interviews that are recorded for accuracy checks are set to automatically start up once the survey begins. A total $20 \%$ of surveys are randomly selected and reviewed by three research members.

\section{Data management and analysis}

To ensure completeness and accuracy of the survey, all questionnaires are administered using GoodData software (GoodData, Beijing, China) on an iPad. The range and logistics of each survey response are set in advance. In addition, users are unable to skip questions, except for logistic reasons. Owing to privacy, all questionnaires are completed by primary caregivers and responses are entered on an iPad by interviewers, except for the CES-D. Interviewers are required to double-check each answer before uploading each completed questionnaire. Once completed, answers cannot be changed owing to preset software limitations; interviewers are required to enter ' 99 ' and to write down the actual answer in a memo and submit it to the data manager.

One primary research member is responsible for data management. Owing to ethical considerations, this project includes all infants of appropriate age. However, only data of qualified infants will be used for further analysis. The preset exclusion criteria are as below.

Children: (1) congenital diseases; (2) disabled; (3) twins or multiple births; (4) premature infants and (5) children who live too far to form a stable group.

Primary caregivers: (1) disabled and (2) caregivers who participate inconsistently in the baseline, mid-term and endline surveys.

The data manager is responsible for data download, correcting the data according to handwritten memos, and blinding treatment allocation and personal information (name and telephone number). Data analysis is conducted separately by two additional project team members using IBM SPSS V.23.0, to assess coherence.

The analysis follows the rules of intention-to-treatanalysis. A paired samples t-test or non-parametric test for indicators in each level of the three surveys is used to test differences between the intervention and control groups. Linear regression is used to identify factors and covariables, and stepwise regression is applied to select variables and their partial correlation coefficients. Path analysis is used to determine potential influencing mechanisms in ECD and to explore indicators and intermediate variables that affect children's development.

\section{ETHICS AND DISSEMINATION}

This study protocol was approved by the Ethical Committee of Capital Institute of Pediatrics, Beijing, China on 10 July 2018 (SHERLL2018014). Village doctors were required to clearly explain to every potential participate the principle of voluntary participation. Informed consent form is required for caregivers in both control and intervention groups. Each child's parent or legal guardian is required to sign the informed consent form after confirming their full understanding of the form. Further findings will be disseminated by presentation and publication. 


\section{PATIENT AND PUBLIC INVOLVEMENT}

Patients and public were not directly involved in the development of the research question or in the design of the study. Village doctors who have plenty experience of parents' / guardian's need for child development were interviewed when designing the intervention. An informed consent is necessary for enrolment. Subjects have the right to withdraw at any time during intervention. Dissemination of general results were made on demand.

\section{DISCUSSION}

With the advantages of helping to create a positive parenting environment and promote peer learning and support, the final goal of the Care Group Intervention is to improve child development by promoting awareness of nurturing and practical capacities among children's primary caregivers. Implementation of this project will fill a gap in the evidence regarding small group-based comprehensive ECD interventions in China. A costeffectiveness analysis will also be conducted. Our research results can not only help to provide additional evidence for ECD economics analyses in China, the present findings can provide a solid evidence-based foundation for the implementation of future national official recommendations and policies.

The limitations of this project are the possible loss to follow-up and limited operational capacity of facilitators. Awareness of the essence of nurturing among rural caregivers is still very low, such that loss or dropout of participants is quite possible, especially with the 1-year intervention cycle. Based on the previous project experience, participants that are lost to follow-up are often those with relatively low development levels or caregivers with lower awareness levels about nurturing, which is precisely why interventions such as that described here are needed. To minimise participant loss or withdrawal, Care Group Intervention training emphasises the importance of continuous attendance and teaches relevant skills, such as warmth and empathy. Trainers are required to use empathy and positive encouragement to create a warm and loving environment for facilitators and to emphasise the importance of environment creation during the entire intervention. In addition, if participants cannot continue owing to illness, distance or other difficulties, facilitators are encouraged to change the intervention location to children's homes, once group members have become familiar with each other. In cases of extreme weather, group activities may be suspended once.

In addition, capacity building among facilitators is a priority for the successful implementation of this project. Trainers are required to use understandable expressions and empathic language to improve facilitators' understanding and enthusiasm. In addition, each facilitator is required and encouraged to invite feedback after each group session and prepare for next two sessions together. Lastly, ongoing training is offered, to assist facilitators in mastering their role within the intervention, so as to ensure scientifically based, interesting and well-organised activities.

\section{Trail status (by the time we submitted)}

Manual translation and adaptation: July 2017 to April 2019.

Research design and pilot study: July 2018 to March 2019

Sample recruitment and baseline survey: April 2019 to June 2019.

Intervention: July 2019 to July 2020.

Midline and endline survey: not started.

Data analysis: not started.

\section{Author affiliations}

${ }^{1}$ Department of Integrated Early Childhood Development, Capital Institute of Pediatrics, Beijing, China

${ }^{2}$ UNICEF China Office, Beijing, China

${ }^{3}$ China Center for Health Development Studies, Peking University, Beijing, China ${ }^{4}$ Center for Global Health (CGH), Colorado School of Public Health, Aurora, Colorado, USA

${ }^{5}$ Beijing Municipal Key Laboratory of Child Development and Nutriomics, Beijing, China

Acknowledgements We would like to express special thanks to a group of Chinese experts who contributed to adaptation and compilation of Care Group Manual, including Zonghan Zhu, Huishan Wang, Weiping Xi, Rongping Li, Jianli Wang, Yuanyuan Xu, Ping Hu and Xiaoyan Wang.We thank Gretchen J. Domek and Maureen Cunningham, Department of Pediatrics, University of Colorado Anschutz Medical Campus and Center for Global Health, Colorado School of Public Health, for training research members and experts according to original Care Group Manual in Beijing in June 2018, as well as offering experiences and lessons in Guatemala.

Contributors MX and HG designed this study and drafted the manuscript. HG, MX and $A L$ edited, selected and designed the intervention materials and carried out the entire study. CZ provided expertise for design nurturing intervention in rural China. HF designed the cost-effectiveness analysis in this study, carried out by his research team. $\mathrm{CZ}$ and $\mathrm{XH}$ contributed to project coordination and evaluation as project experts. SB served as a professional consultant for this study and his research team assisted in training of trainers, as well as problem solving during project design. All authors contributed substantially to revising the manuscript and have read and approved the final manuscript for publication.

Funding This project is funded by Hong Kong Committee for UNICEF China (Programme No: 0860/A0/05/502).

Competing interests None declared.

Patient consent for publication Parental/guardian consent obtained.

Provenance and peer review Not commissioned; externally peer reviewed.

Supplemental material This content has been supplied by the author(s). It has not been vetted by BMJ Publishing Group Limited (BMJ) and may not have been peer-reviewed. Any opinions or recommendations discussed are solely those of the author(s) and are not endorsed by BMJ. BMJ disclaims all liability and responsibility arising from any reliance placed on the content. Where the content includes any translated material, BMJ does not warrant the accuracy and reliability of the translations (including but not limited to local regulations, clinical guidelines, terminology, drug names and drug dosages), and is not responsible for any error and/or omissions arising from translation and adaptation or otherwise.

Open access This is an open access article distributed in accordance with the Creative Commons Attribution Non Commercial (CC BY-NC 4.0) license, which permits others to distribute, remix, adapt, build upon this work non-commercially, and license their derivative works on different terms, provided the original work is properly cited, appropriate credit is given, any changes made indicated, and the use is non-commercial. See: http://creativecommons.org/licenses/by-nc/4.0/.

ORCID iD

Hongyan Guan http://orcid.org/0000-0002-8153-1676 


\section{REFERENCES}

1 Grantham-McGregor S, Cheung YB, Cueto S, et al. Developmental potential in the first 5 years for children in developing countries. Lancet 2007;369:60-70.

2 Shi HF, Zhang JX, Wang XL, et al. [Effectiveness of integrated early childhood development intervention on nurturing care for children aged 0-35 months in rural China]. Zhonghua Er Ke Za Zhi 2018;56:110-5.

3 Gertler P, Heckman J, Pinto R, et al. Labor market returns to an early childhood stimulation intervention in Jamaica. Science 2014;344:998-1001.

4 Walker SP, Chang SM, Vera-Hernández M, et al. Early childhood stimulation benefits adult competence and reduces violent behavior. Pediatrics 2011;127:849-57.

5 Campbell F, Conti G, Heckman JJ, et al. Early childhood investments substantially boost adult health. Science 2014;343:1478-85.

6 Heckman JJ. Schools, skills, and synapses [J]. National Bureau of Economic Research, 2008: 289-324.

7 United Union. Transforming our world: the 2030 agenda for sustainable development, 2015. Available: https://sustainabledevel opment.un.org/post2015/transformingourworld

8 China Development Research Foundation. Report on child development in China 2017: anti-poverty and early childhood development (in Chinese) [M. Chinese Development Press, 2017.

9 Xu M, Liu XH, Zhou XH, et al. Study on rural norm of Bayley Scales of Infant and Toddler Development in Guanzhong, Shaanxi (in Chinese) [J]. Chin J Child Health 2009;02:125-7.

10 Cui Y, Gao JQ, Yue A, et al. [Early childhood development and risk factors in rural China: a cohort study]. Zhonghua Er Ke Za Zhi 2018;56:103-9.

11 Luo R, Shi Y, Zhou H, et al. Anemia and feeding practices among infants in rural Shaanxi Province in China. Nutrients 2014;6:5975-91.

12 The State Council. The outline of program for chinese children's development (2011-2020) [Z], 2011.

13 General Office of the State Council. The plan for the development of children in poor areas (2014-2020) [Z], 2014.

14 General Office of the State Council. The Guidelines of the state council on promoting the development of nurturing care services for children under 3[Z], 2019.

15 Lucas JE, Richter LM, Daelmans B. Care for child development: an intervention in support of responsive caregiving and early child development. Child Care Health Dev 2018;44:41-9.

16 Reach Up. The reach up early childhood parenting programme: origins, conent and implementation[EB/OL]. Available: http://www. reachupandlearn.com/

17 Zhou S, Zhao C, Huang X, et al. The effect of a community-based, integrated and nurturing care intervention on early childhood development in rural China. Public Health 2019;167:125-35.

18 Luo R, Emmers D, Warrinnier N, et al. Using community health workers to deliver a scalable integrated parenting program in rural China: a cluster-randomized controlled trial. Soc Sci Med 2019;239:112545.
19 Luo R, Yue A, Zhou H, et al. The effect of a micronutrient powder home fortification program on anemia and cognitive outcomes among young children in rural China: a cluster randomized trial. BMC Public Health 2017; 17:738.

20 Prost A, Colbourn T, Seward N, et al. Women's groups practising participatory learning and action to improve maternal and newborn health in low-resource settings: a systematic review and metaanalysis. Lancet 2013;381:1736-46.

21 Rosato M, Laverack G, Grabman LH, et al. Community participation: lessons for maternal, newborn, and child health. Lancet 2008;372:962-71.

22 Yousafzai AK, Rasheed MA, Siyal S. Integration of parenting and nutrition interventions in a community health program in Pakistan: an implementation evaluation. Ann N Y Acad Sci 2018;1419:160-78.

23 Hamadani JD, Mehrin SF, Tofail F, et al. Integrating an early childhood development programme into Bangladeshi primary health-care services: an open-label, cluster-randomised controlled trial. Lancet Glob Health 2019;7:e366-75.

24 Shanxi Provincial People's Government. Overview of Shanxi. Available: http://www.stats-sx.gov.cn/tjsj/tjnj/nj2016/indexch.htm

25 shanxi.gov. Shanxi provincial statistical bureau: annual data, 2019. Available: http://tjj.shanxi.gov.cn/sxsj/sxtj/year!list.action? pwebnodesid $=10255$ \& viewRole $=0$

26 Fenxi County People's Governent. The 2018 statistical communique on national economic and social development (in Chinese), 2019. Available: http://www.fenxi.gov.cn/contents/2338/348782.html

27 Domek GJ, Szafran LH, Bonnell LN, et al. Using finger Puppets in the primary care setting to support caregivers talking with their infants: a feasibility pilot study. Clin Pediatr 2020;59:380-7.

28 Qin H, Chen B. National technical specifications for national public services (in Chinese)[M]. People's Medical Publishing House, 2012.

29 Aboud FE, Singla DR, Nahil MI, et al. Effectiveness of a parenting program in Bangladesh to address early childhood health, growth and development. Soc Sci Med 2013;97:250-8.

30 Xu S, Huang H, Zhang J, et al. Research on the applicability of bayley scales of infant and toddler development-third edition to assess the development of infants and toddlers in Shanghai (in Chinese) [J]. Chin J Child Health Care 2011;01.

31 Hua J, Li Y, Ye K, et al. The reliability and validity of Bayley-III cognitive scale in China's male and female children. Early Hum Dev 2019;129:71-8.

32 Stevens GA, Finucane MM, De-Regil LM, et al. Global, regional, and national trends in haemoglobin concentration and prevalence of total and severe anaemia in children and pregnant and nonpregnant women for 1995-2011: a systematic analysis of populationrepresentative data. Lancet Glob Health 2013;1:e16-25.

$33 \mathrm{ASQ}$. Age \& stages questionnaire [EB/OL]. Available: http://www. neoballoon.com/

34 Lu S, Li X, Jiang J, et al. Reliability and validity of the chinese version of IT-HOME (in Chinese) [J]. Chin J Clin Psychol 2018.

35 Sumner G, Spietz A. NCAST caregiver/parent-child interaction manual [M]. Seattle: NCAST Publications, 1994.

36 UNICEF. Multiple indicator cluster survey (MICS) [EB/OL]. Available: https://www.unicef.org/statistics/index_24302.html 